\title{
Experimental study of fast pyrolysis vapors fractionation through different staged condensation configurations
}

\author{
Alessandro Mati ${ }^{1,3}$, Marco Buffi ${ }^{1,2}$, Stefano Dell'Orco ${ }^{1,2}$, M.P. Ruiz Ramiro ${ }^{3}$, S.R.A. Kersten ${ }^{3}$, and David \\ Chiaramonti ${ }^{1,2 *}$ \\ ${ }^{1}$ Industrial Engineering Department (DIEF), Università degli Studi di Firenze, Via S.Marta 3, 50139, Firenze, Italy \\ ${ }^{2}$ RE-CORD (Renewable Energy COnsortium for R\&D), Viale J.F. Kennedy, Pianvallico, 50038, Scarperia e San Piero, Firenze, Italy \\ ${ }^{3}$ Sustainable Process Technology Group, Faculty of Science and Technology, University of Twente, Drienerlolaan 5, 7522NB \\ Enschede, The Netherlands
}

\begin{abstract}
The quality of biocrudes from fast pyrolysis of lignocellulosic biomass can be improved by optimizing the downstream condensation systems to separate and concentrate selected classes of compounds, thus operating different technological solutions and condensation temperatures in multiple condensation stages. Scientific literature reports that fractional condensation can be deployed as an effective and relatively affordable step in fast pyrolysis. It consists in a controlled multiple condensation approach, which aims at the separated collection of classes of compounds that can be further upgraded to bio-derived chemicals through downstream treatments. In this study, fractional condensation has been applied to a fast pyrolysis reactor of $1 \mathrm{~kg} \mathrm{~h}^{-1}$ feed, connected to two different condensation units: one composed by a series of two spray condensers and an intensive cooler; a second by an electrostatic precipitator and an intensive cooler too. Fast pyrolysis of pinewood was conducted in a bubbling fluidized bed reactor at $500{ }^{\circ} \mathrm{C}$, while condensable vapours were collected by an interchangeable series of condensers. Using the first configuration, high boiling point compounds - such as sugars and lignin-derived oligomers - were condensed at higher temperatures in the first stage $\left(100-170{ }^{\circ} \mathrm{C}\right)$, while water soluble lighter compounds and most of the water were condensed at lower temperatures and so largely removed from the bio-oil. In the first two condensing stages, the bio-oil water content remained below $7 \mathrm{wt} \%$ (resulting in $20 \mathrm{MJ} \mathrm{kg}^{-1}$ of energy content) maintaining about $43 \%$ of the liquid yield, compared to the $55 \%$ of the single step condensation runs. The work thus generated promising results, confirming the interest on upscaling the fractional condensation approach to full scale biorefinering.
\end{abstract}

\section{Introduction}

Bio-oil produced from fast pyrolysis of lignocellulosic biomass constitutes (Fast Pyrolysis Bio Oil, FPBO) nowadays a promising renewable alternative to crude oil, potentially representing a sustainable source of both bioenergy and valuable bio-based chemicals. The organic hot vapors produced from the fast pyrolysis process consist of fragments of cellulose, hemicellulose, and lignin polymers derived from the rapid heating of biomass in an inert atmosphere. One way to achieve selective bio-oil fractions of interest consists in taking advantage of the distinct temperatures at which the various organic groups change their state.

Two main different approaches are reported in literature to achieve organic streams separation: the first one is called fractional distillation and operates on the final liquid products of pyrolysis, while the other approach is named fractional condensation and aims to directly condense the produced pyrolysis vapors, resulting in a less energy-expensive process. The latter has the main advantage to limit the thermal energy consumption when compared to distillation, acting directly on a hot vapor streams [1]. Distillation aims at separating bio-oil components according to their different volatilities. Nevertheless, it must be noticed that fast pyrolysis biooils are characterized by thermally instable behavior: reactions already occur below $100{ }^{\circ} \mathrm{C}$. Formation of residues in distillation of bio-oil and can reach values up to $50 \mathrm{wt} \%$ due to cracking and polymerization reactions instead of single components evaporation. This feature is in stark contrast to conventional petroleum derivedfuels, namely diesel and kerosene, which have a up to $90 \mathrm{wt} \%$ distillation yield between $220-300{ }^{\circ} \mathrm{C}$ and 190 $240{ }^{\circ} \mathrm{C}$, respectively [2]. Another study [3] reported that, under atmospheric pressure, bio-oil starts boiling

\footnotetext{
* Corresponding author: david.chiaramonti@polito.it
} 
below $100{ }^{\circ} \mathrm{C}$ and that the distillation process (after being halted at $280^{\circ} \mathrm{C}$ ) leaves roughly $35-50 \mathrm{wt} \%$ of the initial material as a residue. Other distillation techniques, such as vacuum distillation, have been developed for bio-oil applications over the years [4], but this solution remains still inconvenient towards FPBO upgrading. Given that, all separation should be economically and environmentally sensible to ensure that the value of the targeted products exceeds the recovery cost [5]. This implies that the energy demand for recovering a bio-derived fuels should remain a modest fraction of the heating value of the final product itself, thus paving the way for the investigation of alternative approaches. Since the distillation of lignocellulosic pyrolysis oils might not be attractive for the above-mentioned reasons, fractional condensation of bio-oil vapors has been constantly gaining attentions as an effective downstream process to separate the bio-oil constituents [6-8]. Following this approach, the product stream from the fast pyrolysis reactor is passed through a series of condensers maintained at different temperatures to allow the collection of chemically different liquid fractions in each condenser based on their dew point [9]. Variations of condensers temperatures was initially implemented to control the water content of pyrolysis oil [10]. It was found that a higher condenser temperature could be beneficial to the bio-oil quality obtained from a feedstock with higher moisture content by reducing the overall water content. However, the application of a higher condenser temperature could result in a loss of light organics.

The most recent experimental investigations have been focused on separating groups of target compounds present into the bio-oil fractions. Cooling/condensation temperature ranges were determined based on dew points of specific organic groups, thus allowing for the selective and physical separation between each fraction [11]. Controlling nitrogen flow [12] and narrowing cooling temperatures [7] are key features for maximizing the recovery of liquids. At industrial scale, the bio-oil itself is used as condensing medium: however, due to the typical pilot-scale of the experiments available in literature, generally researchers used mineral oils as an indirect cooling medium for example, by circulating it in the first jacketed condensation stage set at the highest cooling temperature $\left(345-110{ }^{\circ} \mathrm{C}\right)$, to control the exit cooling temperature of vapors/aerosols [13]. In general, this paraffinic liquids are employed in direct-spray contact condensers, which exploit the direct mass and heat exchange mechanisms to better control the condensation temperature if compared to the jacketed condensers [7]. The quenching of volatiles in an almost immiscible hydrocarbon solvent eases the determination of mass balance and the compositional analysis of liquids also due to the well-known composition of the mineral oil, as demonstrated by Westerhof et al [11]. In the abovementioned experimental campaign, the SPT group at Twente University has already successfully investigated the upgrading of the fast pyrolysis bio-oil through the fractional condensation of volatiles. Thus, the present work maintained the same experimental layout for spray condensers to investigate the proposed fractional condensation conditions at higher temperatures.

This study focuses on the combination of different condensation systems, varying the liquid products composition, thus serving a more general purpose of generating bio-based intermediates for the production of biofuels and biochemicals. The experimental work, carried out at the University of Twente in the framework of an Academic collaboration with the University of Florence and RE-CORD, was carried out varying only the first step of condensing temperature in the range from 100 to $170{ }^{\circ} \mathrm{C}$ while keeping the other stages at fixed temperature. The aim of the work is to demonstrate how condensing temperatures affect properties and classes separation in the condensed products. Moreover, a specific analysis focused on energy assessment of the overall process is also a major task of this research work, to gain deeper understanding of possible industrial upscaling.

\section{Materials \& methods}

\subsection{Pyrolysis unit}

Experiments were performed in a $1 \mathrm{~kg} \mathrm{~h}^{-1}$ fluidized bed (sand) pyrolysis plant (as already described in [10]) at the SPT group premises at the University of Twente (NL)

The pre-existing layout was specifically modified to meet the required characteristic for the proposed experimental campaign. Biomass feedstock was grinded pine wood (1-2 mm size). During plant operation nitrogen gas flow was fed to the biomass hopper, creating a slight overpressure, which prevented vapors and gases leaving the fluidized bed pyrolysis reactor from flowing back to the hopper via the double screw feeding system.

Sand was continuously fed to control the char holdup and to keep constant the bed height into the reactor.

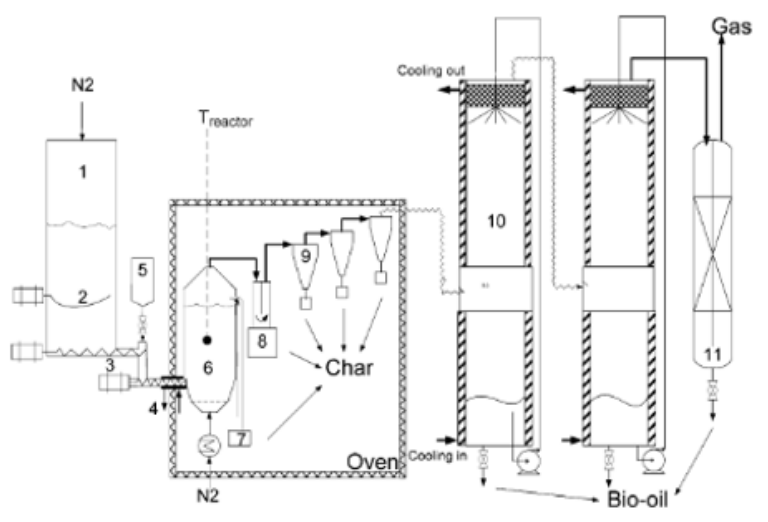

Fig. 1. Schematic layout of the pyrolysis plant connected to the second condensation train: (1) biomass storage hopper; (2) mechanical stirrer; (3) feeding stirrer; (4) cooling jacket; (5) sand storage hopper; (6) fluidized bed reactor; (7) overflow tube + collecting vessel; (8) knock-out vessel (9) [10].

The fluidized bed reactor is made of stainless steel 316 : it has a diameter of $100 \mathrm{~mm}$ and a total height of 420 $\mathrm{mm}$. A mass flow controller was used to set the feed rate 
of the fluidization flow, keeping a constant sand-tobiomass ratio roughly at around 1.5 . Details of the specific condensation trail are described in the next section.

The gaseous stream leaving the condensing section is mainly composed by non-condensable gases and a mixture of aerosols, which are collected in a tubular cotton gas filter $(10 \mu \mathrm{m})$. Finally, a dry gas meter is used to measure the gas flow before the main ventilation system.

The custom bubbling fluidized bed reactor (BFBR) allows a rapid heating of the biomass particles by mixing them in a stream of moving sand particles at high temperatures. The volatile mixing of sand with biomass particles leads to high heat and mass transfer coefficients. The sand bed is indirectly heated being placed in an electric furnace in which two heating zones could be controlled independently.

\subsection{Condensation units}

Two condensation configurations are considered. The first configuration is composted by a thermally controlled ESP (Electrostatic Precipitator) as main condensing system followed by the intensive cooling stage meant to condense the very light vapors. The gaseous stream leaving the tubular reactor is condensed in a custom made jacketed electrostatic precipitator tube with an internal diameter of $6.2 \mathrm{~cm}$ and $44 \mathrm{~cm}$ of length, operating a single electrode at $10 \mathrm{kV}$. Temperature is controlled via circulating pre-heated water inside the ESP outer cylinder. This technology has been widely studied and applied in this field because of its high effectiveness in suspended droplets removal other than overall vapor condensation [14].

The second configuration is composted by a spray condensers train that allows the simultaneous control of three different condensing temperatures in order to divide different boiling fractions present into the hot vapors. First, two counter-current spray condensers are placed in series which exploit the direct-contact heat exchange to maximize liquid yields due to the simultaneous transfer of heat and mass. In depth details of heat exchange mechanism are provided by Dalluge et al. [15]. During the experiments, the temperature of the vapors leaving the condenser and the produced liquids were measured through thermocouples placed at the inlet and the outlet of each section. The residence time of the produced liquids in the collector underneath the condenser (at the condenser's temperature) was approximately $0.5-1 \mathrm{~h}$. A closed-loop spray quench system has been incorporated in the fast pyrolysis pilotscale facility. The selected coolant fluid for this solution is a paraffin oil (Shell Ondina 919), adopted for its thermal stability and poor miscibility with bio-oil. The pressure in the condensers was monitored during all the experiments and was always $1.1 \pm 0.01$ bar.

\subsection{Design of experiment (DOE)}

Experiments have been carried out keeping the fluidized bed reactor temperature fixed at $500{ }^{\circ} \mathrm{C}$ while testing the two different condensation systems, the temperature of the first condenser in the case of the spray columns setup has been varied. First set of three experiments operated with the first condensing configuration. The hot gas stream leaving the reactor $\left(\mathrm{T} \simeq 480^{\circ} \mathrm{C}\right)$ entered into the ESP while its external jacket was heated up to $70{ }^{\circ} \mathrm{C}$. The intensive cooler was kept at a temperature of $-9^{\circ} \mathrm{C}$.

The second configuration has been operated in $\mathrm{nr}$. 5 test runs, with the following operating conditions (as shown in Table 1).

Table 1. Spray condensers experimental campaign.

\begin{tabular}{|c|c|c|c|}
\hline Exp. Code & T $1^{\text {st cond }}$ & T $2^{\text {nd }}$ cond & $\overline{T-I C}$ \\
\hline FC SC1 & $170^{\circ} \mathrm{C}$ & $70^{\circ} \mathrm{C}$ & $-10^{\circ} \mathrm{C}$ \\
\hline FC_SC2 & $170^{\circ} \mathrm{C}$ & $70^{\circ} \mathrm{C}$ & $-10^{\circ} \mathrm{C}$ \\
\hline FC_SC3 & $145^{\circ} \mathrm{C}$ & $70^{\circ} \mathrm{C}$ & $-10^{\circ} \mathrm{C}$ \\
\hline $\mathrm{FC} \_\mathrm{SC} 4$ & $130^{\circ} \mathrm{C}$ & $70^{\circ} \mathrm{C}$ & $-10^{\circ} \mathrm{C}$ \\
\hline FC_SC5 & $100^{\circ} \mathrm{C}$ & $70^{\circ} \mathrm{C}$ & $-10^{\circ} \mathrm{C}$ \\
\hline
\end{tabular}

Efforts are focused in varying the temperature of the first condenser alone, in order to study the condensing behavior of several chemical species which could be interesting to fractionate with the proposed solution. Three bio-liquid cuts have been produced and then analyzed according to the methods shown in the next section

\subsection{Analytical methods}

The application of different analytical techniques was necessary for the characterization of the produced biooil and aqueous phase, for a total of 21 samples.

A GC-MS/FID device (Chromatogram GC 7890A MS 5975C Agilent Technologies) has been utilized as main tool for the compound detection. The machine implements a capillary column Agilent HP-5MS, HP19091S-433 with Helium as carrier gas, an end temperature of $280{ }^{\circ} \mathrm{C}$ and a retention time of 24 minutes. The water content of the different fractions has been investigated via Karl Fisher Titration method (Metrohm 787 KF Titrino).

The elemental composition of 11 samples extracted from the produced different cuts was finally analyzed using a Fisons Instruments 1108 CHNS apparatus. Oxygen has been calculated as difference while ash content has been reasonably assumed as negligible [2].

\section{Results and discussion}

\subsection{Mass balance and yield calculations}

The mass balance closure of the experiments was always above $88 \%$ and below $95 \%$, with an overall average of $92 \%$. Product yields have been determined on an asreceived basis. The overall liquid yields were obtained approximatively equal either for the ESP setup, or the quenching columns systems. The average figures are in good agreement with those shown in literature [16] and can be summarized as follows: $12.7 \%$ of produced char, $62.9 \%$ of bio-oil and a $15.3 \%$ of non-condensable gases. 
The average mass balance closure was calculated at approximately $92 \%$ of the initial feedstock.

Hereafter the distribution of the bio-oil produced among the condensers as a function of the temperature in the first condenser is shown.

For the ESP setup only one temperature $\left(\mathrm{T}_{\text {cond }}=70\right.$ ${ }^{\circ} \mathrm{C}$ ) has been tested for several trials to guarantee procedures and results reproducibility.

Table 2. Reproducibility of three identical experiments, with respect to the reactor conditions $\left(\right.$ Treactor $=500^{\circ} \mathrm{C}$, treactor $=$ $0.6-1.1 \mathrm{~s}$, thot $=0.6-1.1 \mathrm{~s}, \mathrm{fw}$, biomass $=10-12 \%$ ).

\begin{tabular}{lccc}
\hline \multicolumn{1}{c}{$\begin{array}{c}\text { Oil } \\
\text { Fraction }\end{array}$} & $\begin{array}{c}\text { Average } \\
\text { yield, }\end{array}$ & $\begin{array}{c}\text { Std. dev, } \\
\text { Y }\end{array}$ & $\begin{array}{c}\text { Relative } \\
\text { Spread, }\end{array}$ \\
& {$\left[\mathbf{k g} / \mathbf{k g}_{\text {oil }}\right]$} & {$[\mathbf{k g} / \mathbf{k g}$ oil $]$} & $\sigma_{Y} / \boldsymbol{Y} \boldsymbol{x}$ \\
& 55.57 & $5.9 \times 10^{\wedge}-3$ & $1.1 \times 10^{\wedge-2}$ \\
\hline ESP & 43.45 & $7.9 \times 10^{\wedge-3}$ & $1.8 \times 10^{\wedge-2}$ \\
Intensive cooler & 0.99 & $1.4 \times 10^{\wedge-3}$ & $1.5 \times 10^{\wedge-1}$ \\
Gas filter & &
\end{tabular}

Experiments carried out with the ESP have shown good reproducibility (Table 2 ).

Bio-oil mass distribution results are also presented for the operation of the spray condensers setup. Fig. 2 presents the three fractions as for the collecting system where they condensed while also considering the mass fraction of vapors trapped in the last step of the condensation train (i.e. the cotton gas filter).

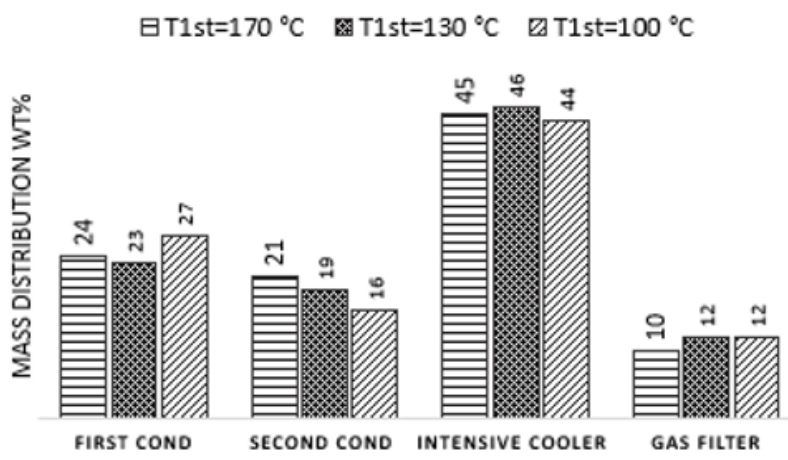

Fig. 2. Mass distribution of bio-oil, Spray Condensers setup.

When operating the first condenser at $100{ }^{\circ} \mathrm{C}$, more than $27 \mathrm{wt} \%$ of the produced liquids condensed at this stage, while at temperatures of $130{ }^{\circ} \mathrm{C}$ and $170{ }^{\circ} \mathrm{C}$, this amount was roughly equal to $23 \mathrm{wt} \%$. The first condenser temperature was varied over a span ranging from $170^{\circ} \mathrm{C}$ to $100{ }^{\circ} \mathrm{C}$ resulting in a trend of increasing amount of collected liquids in the first column as expected for the operated temperature decrease. At higher temperatures liquid yields were slightly lower for the collection of sugars and lignin-derived oligomers in the heavy fraction. At the same time, the variation of first stage temperature influenced the bio-oil yield in the second condenser. This led to an increased mass yield of the $2^{\text {nd }}$ scrubber as the temperature of the $1^{\text {st }}$ condenser was augmented, reaching a maximum value of $21 \mathrm{wt} \%$.
Yields of the last two liquid collectors (i.e. including the gas filter) have shown to settle around a constant value (of $45 \mathrm{wt} \%$ and $11 \mathrm{wt} \%$ respectively) as the temperature never varied during the experimental campaign.

The non-condensable gases generated during the biomass pyrolysis reaction while operating the two spray columns consisted of averaged values of $16 \% \mathrm{O}_{2}$, $47 \% \mathrm{CO}, 22 \% \mathrm{CO}_{2}, 11 \% \mathrm{CH}_{4}$ and $4 \%$ for the $\mathrm{C}_{2}-\mathrm{C}_{3}$ gases. The calorific value of the non-condensable gasstream was very low due to the dilution by the carrier gas (nitrogen). The detected composition showed how the non-condensable gases could be properly reused as fuel gas to self-support the pyrolysis process in a largescale industrial plant [17].

Tests with ESP setup reported the condensation of the largest fraction of bio-oil in the first step, including a high percentage of acidic compounds (up to $40 \mathrm{wt} \%$ of the total amount of detected acids), which are an unwanted feature in terms of bio-fuel aging and storage properties [18]. In the aqueous fraction a high content of acids and a tiny percentage of furanics were identified as well; different analytical approaches could allegedly detect more light organics.

When considering the spray condensers setup, it can be easily noticed that a class-selective separation mechanism happened, leading to the expected fractional condensation of different chemical compound classes. This phenomenon is based on the compounds dew points therefore the heavy, mid-boilers and light fractions behavior is affected by the temperature and technology of condensation. The evolution of the concentration of light compounds, water, and the acids in the oil as well as for sugars and carbonyls obtained in the first and second condenser is significantly influenced by temperature. The content of light compounds, water, and the acids decreases rapidly at an increasing condenser temperature. At a temperature of $170{ }^{\circ} \mathrm{C}$ in the first condenser, the acid fraction in the second collector was only $1.24 \mathrm{wt} \%$, decreasing from 6 wt $\%$ at $100{ }^{\circ} \mathrm{C}$.

Extracting these compounds from the second condenser liquid is beneficial since the recovery of organic compounds at these high concentrations may be economically viable, especially in an aqueous stream containing no oligomers, which makes the extraction process easier. At the same time sugars and ligninderived oligomers were trapped in fraction one, opening to considerations for further utilizations of these compounds via economically rewarding routes.

The observed compositions are in good agreement with other studies, confirming the possibility to tailor the oil composition by varying the temperature of the condensation sections $[6,11,19]$.

\subsection{Water content}

The water content in pyrolysis oil originates both from the initial water content of the feedstock and from dehydration reactions happening during pyrolysis process itself [20]. It lowers oil viscosity, being beneficial for certain applications, while, and most 
important from an energy perspective, it negatively affects the LHV value, in addition to favor phase separation. As expected, no water has been detected in the first condenser during all the fractional condensation experiments (i.e. $\mathrm{T}$ always kept above $100{ }^{\circ} \mathrm{C}$ ). The biooil condensed in the second column showed low amounts of water while preserving good characteristic for biofuel application. Issues related to the high viscosity at room temperature can be overcome by heating up before usage or by adding some methanol to the biocrude. The distribution of water fraction in the final products was influenced by the variation of first condenser temperature, therefore resulting in averaged figure of $69.5 \mathrm{wt} \%$ for the aqueous phase and $6.85 \mathrm{wt}$ $\%$ for the bio-oil itself. Similar results were encountered when operating the ESP-equipped setup: the measured water fraction was $\sim 68 \mathrm{wt} \%$ in the aqueous phase while presenting a value of $5 \mathrm{wt} \%$ for the condensed liquids in the electrostatic precipitator. The aqueous products collected during the experimental campaign at the final stage of every condensation route might be worth of further considerations. Results has shown a prevalence of acidic compounds over the detected ones, mostly acetic acid but also formic acid and others with similar characteristics.

Generally, fast pyrolysis oil obtained via the processing of lignocellulosic biomass, is very acidic in nature and the major component responsible for this property is acetic acid, present in levels up to $2-10 \mathrm{wt} \%$ [21] being responsible for its low $\mathrm{pH}$ value (ca. 2-3). During the experimental campaign, the relatively 'high' condensation temperatures in the second column, which is where the targeted bio-oil is collected, enabled the transfer of most of the acidic compounds into the aqueous phase. Nevertheless, a significative presence of light organics into the aqueous phase can also be reasonably expected since water has been found to constitute less than $72 \mathrm{wt} \%$ of the mixture on average.

\subsection{Energy assessment}

The performed elemental analysis led to in-depth understanding of the distribution of carbon among the different condensed bio-liquids. The initial carbon intake is known to constitute up to $46.58 \%$ of the woody biomass feedstock. Then the process distributes this amount in the produced char, gas and bio oil, resulting in a transfer of the carbon content from raw biomass to bio-oil which accounts for roughly the $30 \%$ of the initial input. This figure is then differently stirred into the final products depending on the condensation route choice.

A significant energy concentration effect was achieved through the fast pyrolysis process coupled with the fractional condensation train of the produced vapors: the lower heating value of bio-oils collected in the second condenser ranged between 19.66 and $20.45 \mathrm{MJ}$ $\mathrm{kg}^{-1}$. The reported values for each experiment were determined by the Channiwala and Parik unified correlation [22]. Fig. 3 shows how the lower heating values have been distributed on average among the three collected bio-oil fractions. A slight difference can be noticed between products collected in the first and second condenser as the temperature of the first was decreased while difference in viscosity became a relevant issue which prevented the operator from an easy removal of the condensed compounds at every step of the tested temperature range $\left(100-170^{\circ} \mathrm{C}\right)$. The second cut visually appeared as single-phase liquid: no phase separation occurred at the moment of extraction neither after several months of storage. It can be therefore concluded that the removal of light organic polar compounds and water did not cause instability of the oils.

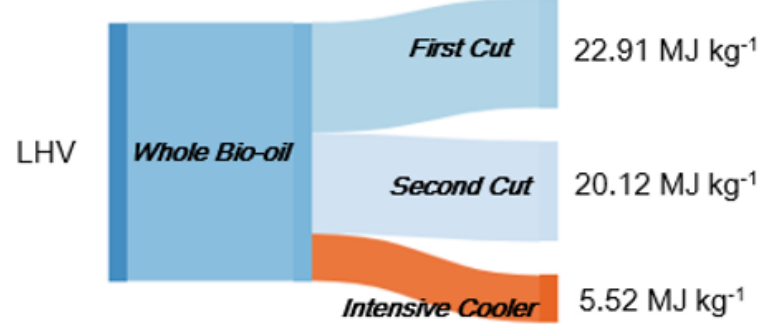

Fig. 3. Lower Heating Value of the three different cuts on average.

In terms of biofuels properties, while the targeted fraction has shown good performances in terms of LHV as well of water content and viscosity, the remaining two fractions should not be underestimated in terms of their energetic recovery potential. Several findings suggest that both the heavy fraction and the aqueous phase show good potential to be precursors of bio-chemicals derived from sugars and acidic compounds respectively. When considering the heavy fraction, levoglucosan, which is widely present, can be hydrolysed to form glucose or can be directly fermented to produce ethanol [23]. The water-insoluble lignin derived oligomers present in the heavy fraction have also the potential to be used for the production of transportation fuels [24] as well as for introducing bio-based materials in products as batteries and supercapacitators applications $[25,26]$.

The middle cut, consisting in the product collected in the second step, showed a significant potential to be upgraded into a biofuel via deoxygenation or by means of blending the bio-oil with renewable ethanol in order to lower its viscosity. LHV values for the second cut and the aqueous phase showed to be rather constant. The average value for the targeted liquid for the bio-fuel application, whether it is intended for direct combustion or for an upgrading path, shows to be in line with the expected results $\left(\simeq 20 \mathrm{MJ} \mathrm{kg}^{-1}\right)$.

Finally, as expected, it was observed that the aqueous phase predominantly contains a large amount of water and various organic compounds such as acetic acid, hydroxyacetone and phenol, which could be further processed to biochemicals as demonstrated in several studies [27-29] Discharging it without treatment not only reduces the bio-energy utilization rate, but also pollutes the environment. 


\subsection{Energy balances}

Since the experimental campaign has shown promising results for an upscale of the fractional condensation system, considerations about energy and mass balances of the overall process are also discussed. These reported figures are derived from the averaged data collected via the experimental campaign.

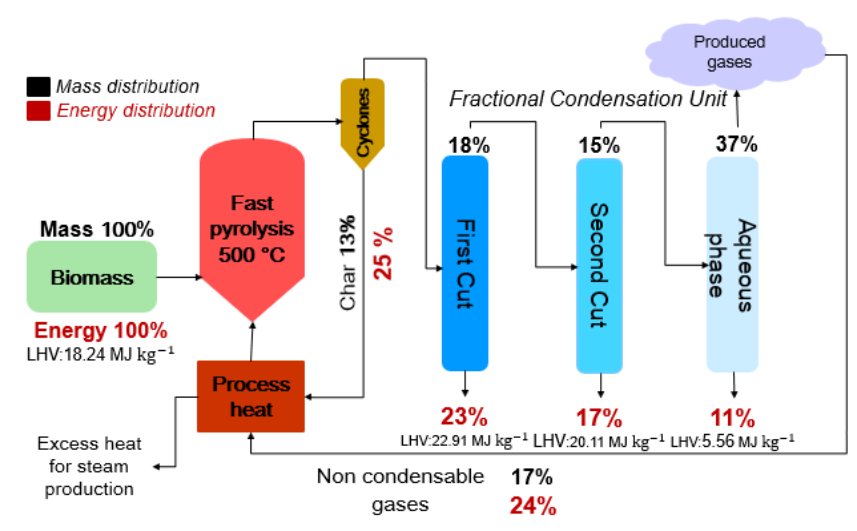

Fig. 4. Mass and energy balances of a commercial-scale plant with fractional condensation system.

As shown in Fig. 4, mass and energy balances of the are applied to the full-scale scheme and the expected distribution of products streams is presented as a percentage of the initial feedstock (assumed at 100 wt \%). While char and non-condensable gases would account for roughly $30 \%$ of the mass balance, the bio-oil production yield is expected to hit the $70 \mathrm{wt} \%$ of the initial woody biomass.

From an energy standpoint the first two fractions (i.e. excluding the aqueous phase) account for the $40 \%$ of total energy (with an LHV of 22.91 and $20.11 \mathrm{MJ} \mathrm{kg}^{-}$ ${ }^{1}$ respectively) while representing the 33 wt $\%$ of the initial mass. These findings therefore suggest that the conversion from solid to liquid has the potential to achieve a good efficiency. The present layout demonstrated that consistent amount of energy outputs can be recovered in different bio-oil cuts, favoring further upgrading processes. According to Castello et al. [30] a lower hydrogen demand for a potential downstream upgrading process such as hydrotreatment can be achieved using the proposed strategy.

\section{Conclusion}

Findings of the current study support that fractional condensation applied to lignocellulosic fast pyrolysis is a promising and cheap downstream approach to concentrate classes of compounds, aiming to control the quality of collected bio-oil fractions. A fractional condensation train was customized at the University of Twente and operated to achieve the condensation and separation of specific bio-oil key-compound classes.

The counter current spray condensers allowed for well-controlled fractional condensation because of the reaching of near-equilibrium conditions. The spray principle showed to be very effective in aerosols collection due to the development of a sufficiently wide contact surface. Bio-oil yields in the quenching columns were observed to slightly vary with the condensing temperature. The identified trend confirms to be linked to the temperature decrease, resulting in higher yields at lower temperature of condensation as the dew points of chemical compounds and the flash condensation theory can well unfold.

The energy content of the collected fractions has nonetheless shown to remain rather constant over the temperature variation of the first scrubber. This entails a consideration over the necessity of reaching such high temperature on the first stage. More likely, a good tradeoff between energy efficiency and products quality could result in setting the first spray column temperature at about $130{ }^{\circ} \mathrm{C}$. The implemented condensation scheme seemed to achieve promising results in terms of the energy outputs of the different bio-oil cuts while at the same time favoring post-processing requirements such as the necessity of a lower hydrogen input for hydrotreatment process.

In conclusion, this type of condensation solutions might have potential to be implemented in a biorefinery: while biofuel production remains the core purpose, it is the related bio-chemicals production that could provide additional source of revenue and improve the economic feasibility of the system on a commercial scale in a selfsustainable perspective of the process. This however requires a detailed market assessment potential for the different condensed fractions. Further investigations through techno-economic analysis (TEA) are needed to validate the economic advantages of co-products extraction in a full scale biorefinery perspective.

\section{Reference}

[1] A.A. Kiss, J. Lange, B. Schuur, D.W.F. Brilman, A.G.J. Van Der Ham, S.R.A. Kersten, Separation technology-Making a difference in biorefineries, Biomass and Bioenergy. 95 (2016) 296-309. doi:10.1016/j.biombioe.2016.05.021.

[2] J. Lehto, A. Oasmaa, Y. Solantausta, M. Kytö, D. Chiaramonti, Review of fuel oil quality and combustion of fast pyrolysis bio-oils from lignocellulosic biomass, Appl. Energy. 116 (2014) 178-190. doi:10.1016/j.apenergy.2013.11.040.

[3] S. Czernik, A. V Bridgwater, Overview of Applications of Biomass Fast Pyrolysis Oil, (2004) 590-598. doi:10.1021/ef034067u.

[4] J. Kim, Production, separation and applications of phenolic-rich bio-oil - A review, Bioresour. Technol. 178 (2015) 90-98. doi:10.1016/j.biortech.2014.08.121.

[5] L.Y. Garcia-chavez, C.M. Garsia, B. Schuur, A.B. De Haan, Biobutanol Recovery Using Nonfluorinated Task-Specific Ionic Liquids, (2012). doi:10.1021/ie201855h.

[6] A.S. Pollard, M.R. Rover, R.C. Brown, J. Anal. Appl. Pyrolysis. 93 (2012) 129-138. doi:10.1016/j.jaap.2011.10.007. 
[7] T. Chen, C. Deng, R. Liu, Effect of selective condensation on the characterization of bio-oil from pine sawdust fast pyrolysis using a fluidized-bed reactor, Energy and Fuels. 24 (2010) 6616-6623. doi:10.1021/ef1011963.

[8] P.T. Williams, A.J. Brindle, Temperature selective condensation of tyre pyrolysis oils to maximise the recovery of single ring aromatic compounds, Fuel. 82 (2003) 1023-1031. doi:10.1016/S0016-2361(03)00016-4.

[9] A. Tumbalam Gooty, D. Li, C. Briens, F. Berruti, Fractional condensation of bio-oil vapors produced from birch bark pyrolysis, Sep. Purif. Technol. 124 (2014) 81-88. doi:10.1016/j.seppur.2014.01.003.

[10] R.J.M. Westerhof, N.J.M. Kuipers, S.R.A. Kersten, W.P.M. Van Swaaij, Controlling the water content of biomass fast pyrolysis oil, Ind. Eng. Chem. Res. 46 (2007) 9238-9247. doi: $10.1021 / \mathrm{ie} 070684 \mathrm{k}$.

[11] R.J.M. Westerhof, D.W.F. Brilman, M. GarciaPerez, Z. Wang, S.R.G. Oudenhoven, W.P.M. Van Swaaij, S.R.A. Kersten, Fractional condensation of biomass pyrolysis vapors, Energy and Fuels. 25 (2011) 1817-1829. doi:10.1021/ef2000322.

[12] H.S. Grecel, Production and characterization of pyrolysis liquids from sunflower-pressed bagasse., Bioresour. Technol. (2003) 113-117.

[13] B. Bronson, D. Mazerolle, T. Robinson, Consequences of using an immiscible quench fluid for engineering scale $R \& D$ in fast pyrolysis, Pyne 45. (2019) 1-33.

[14] R.J. Bedmutha, L. Ferrante, C. Briens, F. Berruti, I. Inculet, Single and two-stage electrostatic demisters for biomass pyrolysis application, Chem. Eng. Process. Process Intensif. 48 (2009) 1112-1120. doi:10.1016/j.cep.2009.02.007.

[15] D.L. Dalluge, L.E. Whitmer, J.P. Polin, Y.S. Choi, B.H. Shanks, R.C. Brown, Comparison of direct and indirect contact heat exchange to improve recovery of bio-oil, Appl. Energy. 251 (2019) 113346.

doi:10.1016/j.apenergy.2019.113346.

[16] A. V. Bridgwater, Review of fast pyrolysis of biomass and product upgrading, Biomass and Bioenergy. 38 (2012) 68-94. doi:10.1016/j.biombioe.2011.01.048.

[17] BTG, Fast pyrolysis, (n.d.). https://www.btgworld.com/en/rtd/technologies/ fast-pyrolysis.

[18] M. Siriwardhana, Fractional condensation of pyrolysis vapours as a promising approach to control bio-oil aging : Dry birch bark bio-oil, Renew. Energy. 152 (2020) 1121-1128. doi:10.1016/j.renene.2020.01.095.

[19] B. Peterson, C. Engtrakul, A.N. Wilson, S.D. Orco, K.A. Orton, S. Deutch, M.M. Yung, A.K. Starace, Y. Parent, D. Chiaramonti, K.A.
Magrini, Catalytic Hot-Gas Filtration with a Supported Heteropolyacid Catalyst for Preconditioning Biomass Pyrolysis Vapors, ACS Sustain. Chem. Eng. 7 (2019) 1494114952. doi:10.1021/acssuschemeng.9b03188.

[20] A. Oasmaa, S. Czernik, Fuel oil quality of biomass pyrolysis oils - state of the art for the end users, Energy and Fuels. 13 (1999) 914 921. doi:10.1021/ef980272b.

[21] F.H. Mahfud, F.P. Van Geel, R.H. Venderbosch, H.J. Heeres, Acetic acid recovery from fast pyrolysis oil. An exploratory study on liquid-liquid reactive extraction using aliphatic tertiary amines, Sep. Sci. Technol. 43 (2008) 3056-3074. doi:10.1080/01496390802222509.

[22] S.A. Channiwala, P.P. Parikh, Fuel. 81 (2002) 1051-1063. doi:10.1016/S00162361(01)00131-4.

[23] J. Lian, S. Chen, S. Zhou, Z. Wang, J. O'Fallon, C.Z. Li, M. Garcia-Perez, Separation, hydrolysis and fermentation of pyrolytic sugars to produce ethanol and lipids, Bioresour. Technol. 101 (2010) 9688-9699. doi:10.1016/j.biortech.2010.07.071.

[24] F. De Miguel Mercader, M.J. Groeneveld, S.R.A. Kersten, C. Geantet, G. Toussaint, N.W.J. Way, C.J. Schaverien, K.J.A. Hogendoorn, Hydrodeoxygenation of pyrolysis oil fractions: Process understanding and quality assessment through co-processing in refinery units, Energy Environ. Sci. 4 (2011) 985-997. doi:10.1039/c0ee00523a.

[25] J. Zhu, C. Yan, X. Zhang, C. Yang, M. Jiang, $\mathrm{X}$. Zhang, A sustainable platform of lignin : From bioresources to materials and their applications in rechargeable batteries and supercapacitors, Prog. Energy Combust. Sci. $76(2020) 100788$. doi:10.1016/j.pecs.2019.100788.

[26] Y. Zhang, Z. Gao, N. Song, J. He, X. Li, Graphene and its derivatives in lithium e sulfur batteries, Mater. Today Energy. 9 (2018) 319335. doi:10.1016/j.mtener.2018.06.001.

[27] Q. Smejkal, D. Linke, M. Baerns, Energetic and economic evaluation of the production of acetic acid via ethane oxidation, Chem. Eng. Process. Process Intensif. 44 (2005) 421-428. doi:10.1016/j.cep.2004.06.004.

[28] A. Teella, G.W. Huber, D.M. Ford, Separation of acetic acid from the aqueous fraction of fast pyrolysis bio-oils using nanofiltration and reverse osmosis membranes, J. Memb. Sci. 378 (2011) 495-502. doi:10.1016/j.memsci.2011.05.036.

[29] S.P. Zhang, X.J. Li, Q.Y. Li, Q.L. Xu, Y.J. Yan, Hydrogen production from the aqueous phase derived from fast pyrolysis of biomass, J. Anal. Appl. Pyrolysis. 92 (2011) 158-163. doi:10.1016/j.jaap.2011.05.007. 
[30] D. Castello, L. Rosendahl, Coprocessing of pyrolysis oil in refineries, Elsevier Ltd., 2018. doi:10.1016/B978-0-08-101029-7.00008-4. 